\title{
Q6e
}

Juan Carlos Guajardo Beltrán*

Matías Marañón Luco**

\section{MINERÍA EN CHILE Significado para la economía chilena, riesgos y oportunidades}

El presente artículo ilustra el desarrollo que la minería ha tenido en Chile, su relevancia económica y situación actual. A través del conocimiento adquirido por el estrecho contacto con la industria minera en Chile, además de la revisión bibliográfica y el estudio de estadísticas públicas, se ha logrado definir los seis principales riesgos y oportunidades para el sector: productividad y costos, capacidad de renovación de proyectos, disponibilidad de insumos críticos, estrategia versus visión cortoplacista, Codelco como pieza fundamental del modelo minero del país y desarrollo de la mediana minería. Será relevante, para la solución de estos asuntos, la capacidad que tenga Chile de superar la desconexión entre la sociedad y esta actividad e instalar en la discusión pública la gran oportunidad que representa la posibilidad de generar una plataforma de desarrollo productivo de largo plazo a partir de la minería.

Palabras clave: productividad, costos, exploración, estrategia, cortoplacista, mediana minería. Códigos JEL: L72, O47.

\section{Introducción}

A lo largo de la historia de Chile se han sucedido diversas etapas en las cuales la explotación de un recurso mineral ha sido protagonista del devenir económico-social del país. Hoy en día, es también incuestionable la gran relevancia que el sector minero tiene en la economía de Chile. No obstante, el país experimenta una etapa de cambios, los cuales están generando crecientes desafíos en la industria minera y que podrían afectar a su aporte sobre la economía.

* Director Ejecutivo. Plusmining

** Analista de Mercado y Estrategia. Plusmining.

Versión de febrero de 2017.
El término del superciclo de las materias primas (2003-2011) puso en evidencia las falencias e incertidumbres que hoy afectan a la industria minera, así como las oportunidades que no han sido aprovechadas. En esta reconfiguración que requiere la industria aparecen seis aspectos relevantes que merecen ser tratados por el sector, y que son: productividad y costos, capacidad de renovación de proyectos, disponibilidad de insumos críticos, estrategia versus visión cortoplacista, Codelco como pieza fundamental del modelo minero del país y desarrollo de la mediana minería.

Por lo tanto, la continuidad y el crecimiento del sector requerirán condiciones distintas que permitan mitigar y controlar los principales $\triangle$ 
riesgos que hoy en día afectan a la industria, así como aprovechar oportunidades aún no explotadas al máximo.

Muy relevante será para la solución de estos desafíos la capacidad que tenga Chile de superar la paradójica desconexión entre la sociedad y esta actividad, y por otro lado instalar en la discusión pública la gran oportunidad que representa la posibilidad de generar una plataforma de desarrollo a largo plazo a partir de la minería.

\section{Historia de la minería en Chile}

Chile ha tenido históricamente una marcada relación con la minería. Gran parte de la motivación por conquistar y luego colonizar su territorio se explica a través del interés de España en ampliar las fronteras para la explotación de riquezas naturales desde el Virreinato del Perú. A lo largo de la historia moderna de Chile se han sucedido diversas etapas en las que la explotación de un recurso mineral ha sido protagonista del devenir económico-social del país, convirtiendo la minería en pilar y columna vertebral de su desarrollo económico y político.

Durante el siglo xvı la efímera explotación de lavaderos de oro explicó el origen de la primera colonización del país. Luego, la revolución industrial europea en el siglo xIx incrementó significativamente la producción y exportación de cobre, junto a la mayor expansión productiva que se dio por la masiva apertura al exterior ocurrida después de la independencia. Esta etapa estuvo marcada por el aumento de la producción de plata ${ }^{1}$, el auge del cobre y el surgimiento de la producción de

1 El periodo $1830-1880$ es conocido como el ciclo de la plata. carbón. En el caso del cobre, Chile se benefició a partir de 1850 de la creciente demanda mundial y del desarrollo tecnológico de la industria de fundición. Pero, sin duda, fue el salitre el principal producto minero del siglo xIx y comienzos del xx, llegando a representar el 56 por 100 de los ingresos fiscales.

Para la minería, el siglo $x x$ fue el siglo del cobre. La llegada de capital estadounidense en las primeras décadas permitió la explotación a gran escala, sin embargo planteó también interrogantes políticas, sobre todo respecto al dilema entre la capacidad empresarial nacional para desarrollar esta industria versus el rol del capital extranjero para impulsarla. Lo anterior también se vio reflejado en un creciente interés del Estado por controlar y participar de esta industria clave en la economía del país. Así fue como en 1955 se formuló la llamada «Política del Nuevo Trato», que garantizó un ingreso mínimo al Estado desde la gran minería. En 1964, se profundizó en dicha política con la llamada «Chilenización», por la cual Chile se asoció -con participación mayoritaria- al capital norteamericano. En 1971, mediante una reforma constitucional, se nacionalizaron las empresas de la gran minería, creándose la Corporación Nacional del Cobre de Chile (Codelco).

Durante el régimen militar que gobernó Chile en el periodo 1973-1990, coexistieron dos visiones contrapuestas, a saber: una nacionalista y otra liberal que reclamaba la apertura del sector minero a capitales extranjeros. Este conflicto se saldó con la coexistencia de un sector productivo público (Codelco) y la apertura de los recursos mineros a la inversión privada, a través de una serie de reformas institucionales, esquema que dura hasta hoy. 


\section{Geología de Chile y su potencial}

Las favorables condiciones para la minería en Chile se explican por la evolución geológica de su territorio, la cual es consecuencia de la alta actividad de subducción entre las placas de Nazca y la Sudamericana. Esta actividad es el origen de la mayoría de los yacimientos minerales del país, siendo los pórfidos cupríferos (ubicados desde el norte hasta la Región del Maule, en la cordillera de los Andes; ver Gráfico 1) los más relevantes debido a su calidad tanto en tamaño como en leyes.

En Chile existen además gran cantidad de yacimientos de oro y plata, entre los que destacan especialmente los de la zona de la cordillera andina de la Región de Atacama, siendo importantes también en esta región los yacimientos de hierro y manganeso. En cuanto a minería no metálica, el territorio de Chile está dotado singularmente de recursos comerciales naturales de nitratos, yodo, litio y potasio. La Tabla 1 detalla la producción y reservas de minerales en Chile, y las compara con el resto del mundo, ilustrando la $D$

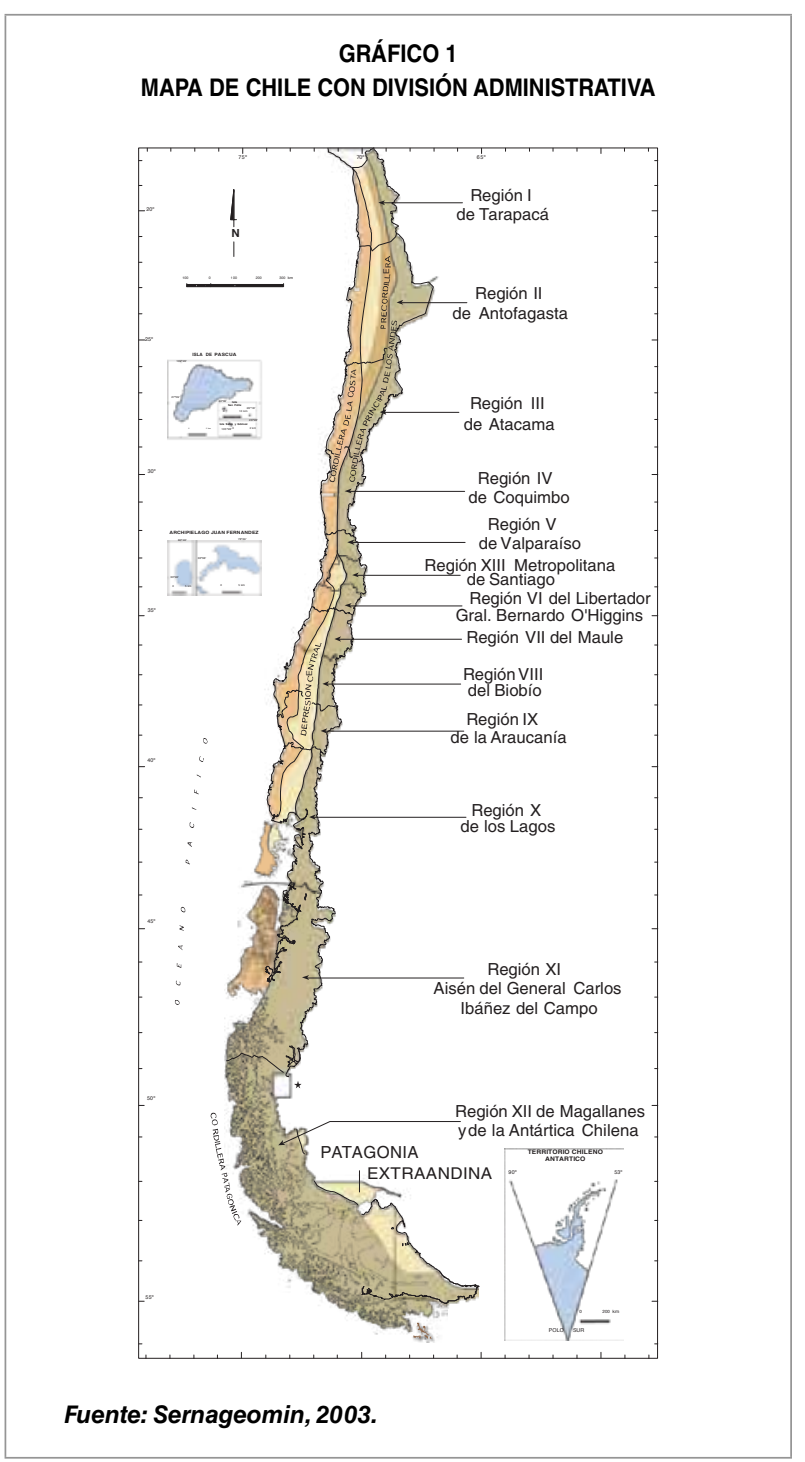

TABLA 1

PRODUCCIÓN ANUAL Y RESERVAS

\begin{tabular}{|c|c|c|c|c|c|c|}
\hline & \multicolumn{3}{|c|}{ Producción anual 2016* } & \multicolumn{3}{|c|}{ Reservas $^{\star \star}$ a 2016} \\
\hline & Chile & Mundo & Porcentaje & Chile & Mundo & Porcentaje \\
\hline Cobre [kMT Cu] & 5.500 & 19.400 & 28 & 210.000 & 720.000 & 29 \\
\hline Molibdeno [MT Mo] & 52.000 & 227.000 & 23 & 1.800 .000 & 15.000 .000 & 12 \\
\hline Oro [MT Au] & $43^{\star \star \star}$ & 3.100 & 1 & $956^{\star \star \star \star}$ & 57.000 & 2 \\
\hline Plata [MT Ag] & 1.500 & 27.000 & 6 & 77.000 & 570.000 & 14 \\
\hline Litio [MT] & 12.000 & 35.000 & 34 & 7.500 .000 & 14.000 .000 & 54 \\
\hline Yodo [MT] & 21.000 & 31.600 & 66 & 1.800 .000 & 7.500 .000 & 24 \\
\hline Boro [kMT] & 500 & 9.400 & 5 & 35.000 & 380.000 & 9 \\
\hline Renio [kg] & 26.000 & 47.200 & 55 & 1.300 .000 & 2.500 .000 & 52 \\
\hline \multicolumn{7}{|c|}{$\begin{array}{l}\text { MT: toneladas métricas. } \\
\text { * Solo se consideraron los commodities, en donde Chile tiene una participación mundial igual o superior al } 1 \text { por } 100 . \\
{ }^{\star *} \text { Porción de los yacimientos que es económica y técnicamente viable de explotar. } \\
\star \star * \text { Producción de } 2015 \text {. } \\
{ }^{\star * \star *} \text { Estimación realizada en } 2007 \text {. }\end{array}$} \\
\hline
\end{tabular}


TABLA 2

PRODUCCIÓN DE MINERALES EN CHILE

\begin{tabular}{|c|c|c|c|c|c|c|c|c|}
\hline & Mineral & 1995 & 2000 & 2005 & 2010 & 2015 & $\begin{array}{c}\text { Crecimiento } \\
1995-2015(\%)\end{array}$ & $\begin{array}{c}\text { Crecimiento } \\
\text { Anualizado (\%) }\end{array}$ \\
\hline \multirow{6}{*}{$\begin{array}{l}\frac{\mathbb{J}}{\frac{\pi}{\pi}} \\
\frac{\pi}{\Sigma}\end{array}$} & Cobre [KMt] & 2.489 & 4.602 & 5.321 & 5.419 & 5.764 & 132 & 4,3 \\
\hline & Molibdeno [MT] & 17.889 & 33.187 & 48.041 & 37.186 & 52.579 & 194 & 5,5 \\
\hline & Oro [Kg] & 44.585 & 54.143 & 40.447 & 39.494 & 42.501 & -5 & $-0,2$ \\
\hline & Plata [MT] & 1.041 & 1.242 & 1.400 & 1.287 & 1.504 & 44 & 1,9 \\
\hline & Plomo [MT] & 944 & 785 & 878 & 695 & 2.979 & 216 & 5,9 \\
\hline & Hierro [kMT] & 8.432 & 5.398 & 4.707 & 6.805 & 9.148 & 8 & 0,4 \\
\hline \multirow{4}{*}{ 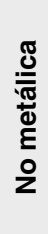 } & Boro [MT] & 211.312 & 347.797 & 469.457 & 503.609 & 517.584 & 145 & 4,6 \\
\hline & Litio [MT] & 12.943 & 35.869 & 44.276 & 52.851 & 56.375 & 336 & 7,6 \\
\hline & Potasio [MT] & 84.290 & 790.587 & 895.916 & 1.525 .996 & 1.889 .075 & 2.141 & 16,8 \\
\hline & Yodo [MT] & 5.103 & 10.474 & 15.346 & 15.793 & 21.179 & 315 & 7,4 \\
\hline
\end{tabular}

TABLA 3

EXPORTACIONES MINERAS [Millones US\$ FOB]

\begin{tabular}{|c|c|c|c|}
\hline Producto & 2007 & 2011 & 2015 \\
\hline Cobre & 37.913 & 43.614 & 30.371 \\
\hline Resto de la minería metálica & 5.610 & 5.693 & 2.692 \\
\hline Minería no metálica & 637 & 1.152 & 1.053 \\
\hline Otros & 34 & 137 & 285 \\
\hline Total de exportaciones mineras & 44.194 & 50.597 & 34.400 \\
\hline Participación del cobre en las exportaciones mineras (porcentaje) & 86 & 86 & 88 \\
\hline
\end{tabular}

relevancia que Chile tiene en la actualidad como proveedor de recursos minerales y su potencial.

\section{Importancia de la minería en la economía chilena}

La evolución que ha tenido la industria minera en Chile en las últimas tres décadas se puede caracterizar como de fuerte expansión, especialmente en los años noventa, período conocido como el «boom de la minería chilena», cuando los volúmenes de producción de cobre y otros recursos minerales creció intensamente (Tabla 2). El motivo del crecimiento del sector en este período fue una combinación entre la disponibilidad de proyectos sin desarrollar ${ }^{2}$ y el posterior gran aumento de demanda mundial de minerales impulsado por $\triangleright$

2 A fines de los ochenta, en Chile existía un gran número de proyectos de calidad que no se habían desarrollado por razones de riesgo político y que con el retorno de la democracia en 1990 ofrecieron a los inversionistas un marco de estabilidad que incentivó la materialización de la inversión en ellos. 


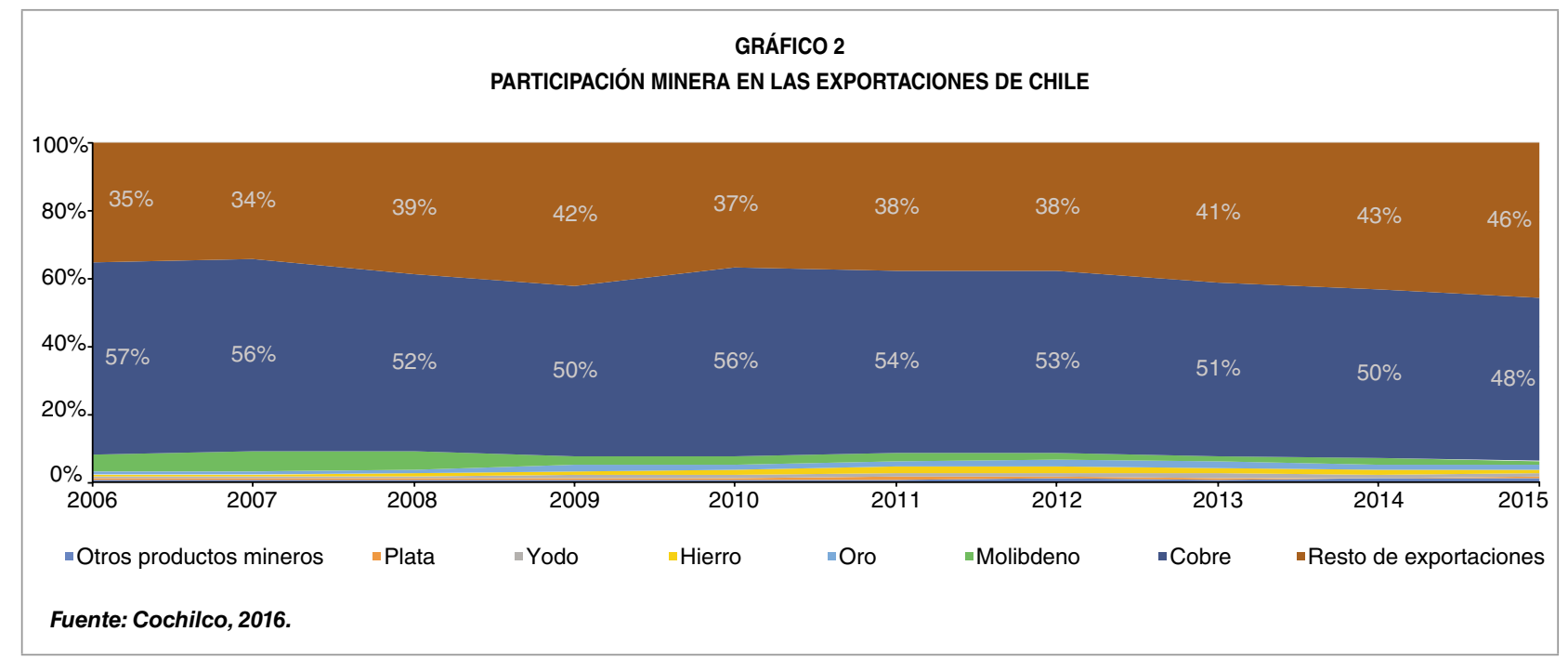

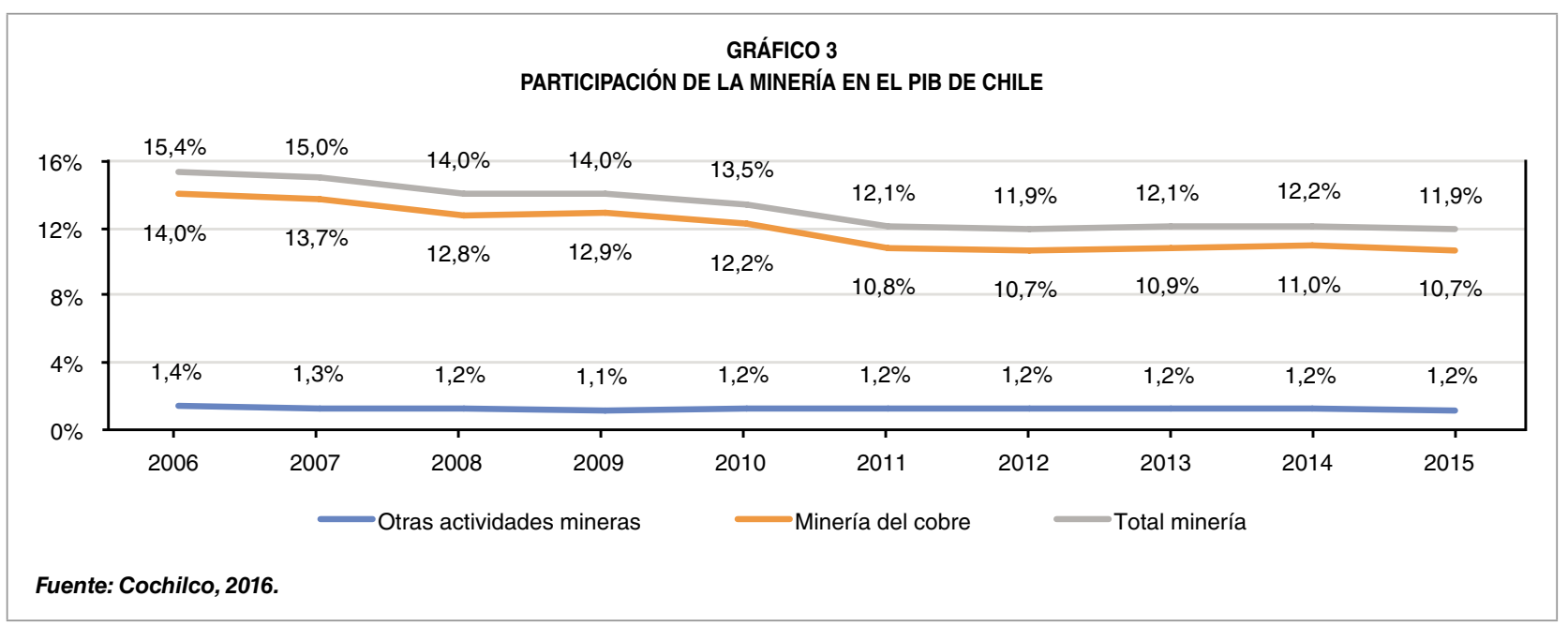

el crecimiento de China ${ }^{3}$ (actualmente consume alrededor del 45 por 100 de la producción mundial de cobre).

Al observar en la Tabla 3 las exportaciones de la industria minera en los últimos años, se concluye que el cobre es el commodity más relevante para Chile.

El Gráfico 2 refuerza la idea de que la industria del cobre es muy relevante para el país, pues explica el 53 por 100 (promedio de los últimos diez años) de las exportaciones de Chile.

3 El crecimiento económico que China experimentó en los noventa impactó el mercado mundial de los commodities a partir de 2003, generando el conocido superciclo de las materias primas entre 2003 y 2015.
En el Gráfico 3 se puede observar la importancia de la minería medida como porcentaje del producto interno bruto (PIB). El promedio para la última década es de un 13,2 por 100, siendo 12 puntos explicados por la industria del cobre. Es importante mencionar que la caída observada, tanto en el Gráfico 2 como en el Gráfico 3, se explica principalmente por la disminución en el precio de las materias primas ocurrida en los últimos años.

Desde el punto de vista de los ingresos al fisco, la minería ha entregado en promedio 8.962 millones de USD $^{4}$ anuales al fisco $\triangleright$

\footnotetext{
4 Deflactado con el IPC de Estados Unidos, año base 2015.
} 


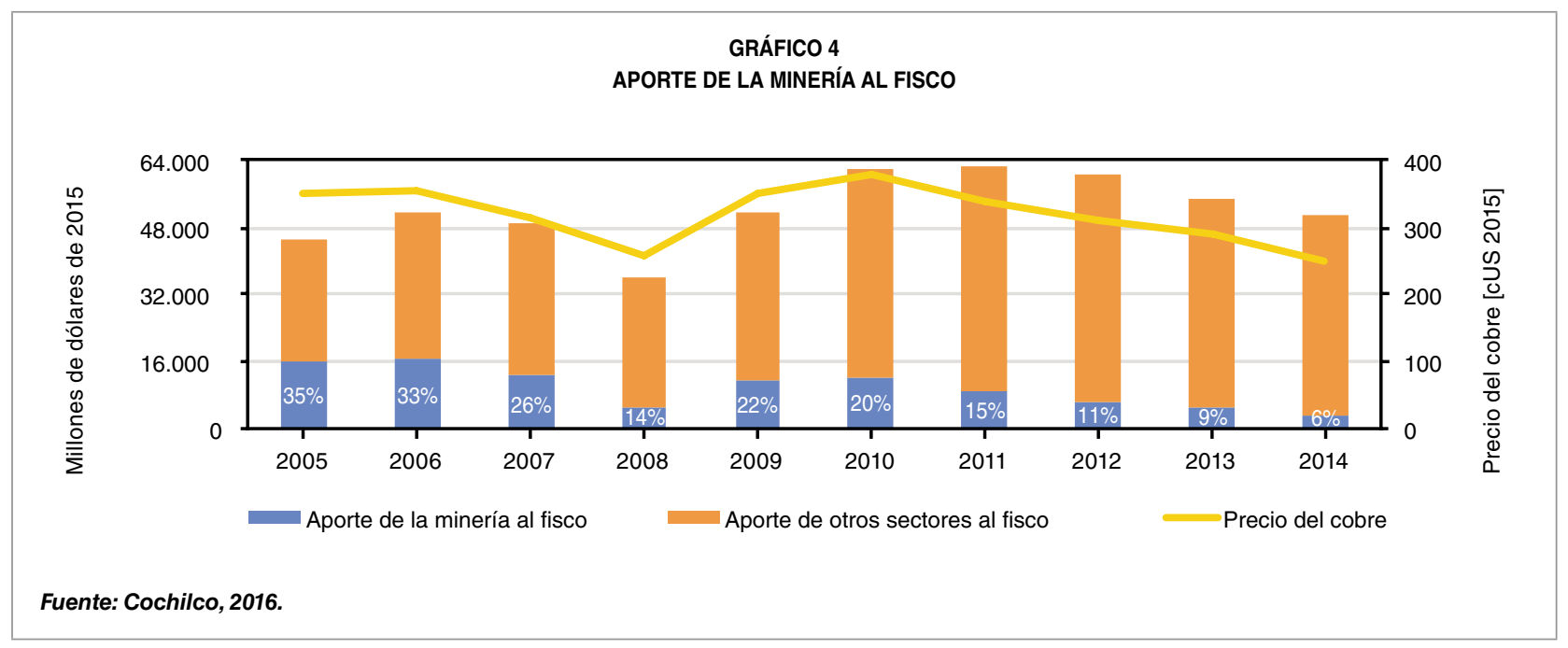

(19 por 100 de participación sobre el periodo de análisis). Sin embargo, debido al gran impacto que los precios de los commodities, específicamente el precio del cobre, tienen sobre este indicador $^{5}$, en los últimos diez años los ingresos fiscales han fluctuado aproximadamente entre los 16.900 millones de USD (2007) y los 3.200 millones de USD $(2015)^{6}$, ambos en dólares del 2015. Es muy importante mencionar que el sector minero en Chile tiene un alto impacto indirecto dentro de la economía, lo que hace que el efecto combinado en los ingresos fiscales esté fuertemente correlacionado con el precio del cobre, como se puede inferir del Gráfico 4.

\section{La nueva etapa de la industria minera en Chile}

Es incuestionable la gran relevancia que el sector minero tuvo y tiene en la economía de

\footnotetext{
5 La correlación entre el precio del cobre y el aporte de la minería al fisco sobre el periodo 1996-2015 es de un 86 por 100 .

6 Chile cuenta con un mecanismo llamado Fondo de Estabilización Económica y Social (FEES) cuyo objetivo es estabilizar las finanzas públicas ante fluctuaciones de la economía y los ingresos fiscales. Este mecanismo ha supuesto uno de los mayores progresos de política económica en la historia del país, ya que ha permitido mitigar el impacto de las fluctuaciones cíclicas de los precios de las materias primas en el ciclo económico del país.
}

Chile. No obstante, el país experimenta una etapa de cambios, los cuales están generando crecientes desafíos en la industria minera y que podrían afectar a su aporte sobre la economía.

En el plano político, la alternancia ocurrida en la penúltima elección presidencial marcó un hito efectivo en la transición política y social posdictadura que cerró el periodo de consensos que fue favorable para las políticas económicas proinversión, abriendo espacio para la manifestación de demandas contenidas y tensiones incubadas por largo tiempo. Sin embargo, en los últimos años se ha intensificado la incertidumbre, con baja legitimidad del sistema político.

Por otra parte, las crecientes demandas de una sociedad emergente que ha mejorado su calidad de vida, gracias en gran parte al aporte de la fuerte expansión de la minería, están cambiando el marco que prevaleció en las décadas anteriores para el funcionamiento de la industria minera en Chile. Los permisos para la inversión y la operación son más difíciles de obtener y las exigencias a su aporte al país son mayores. Este cambio social coincide con una fase de deterioro de las condiciones de competitividad de la industria nacional en $\triangleright$ 


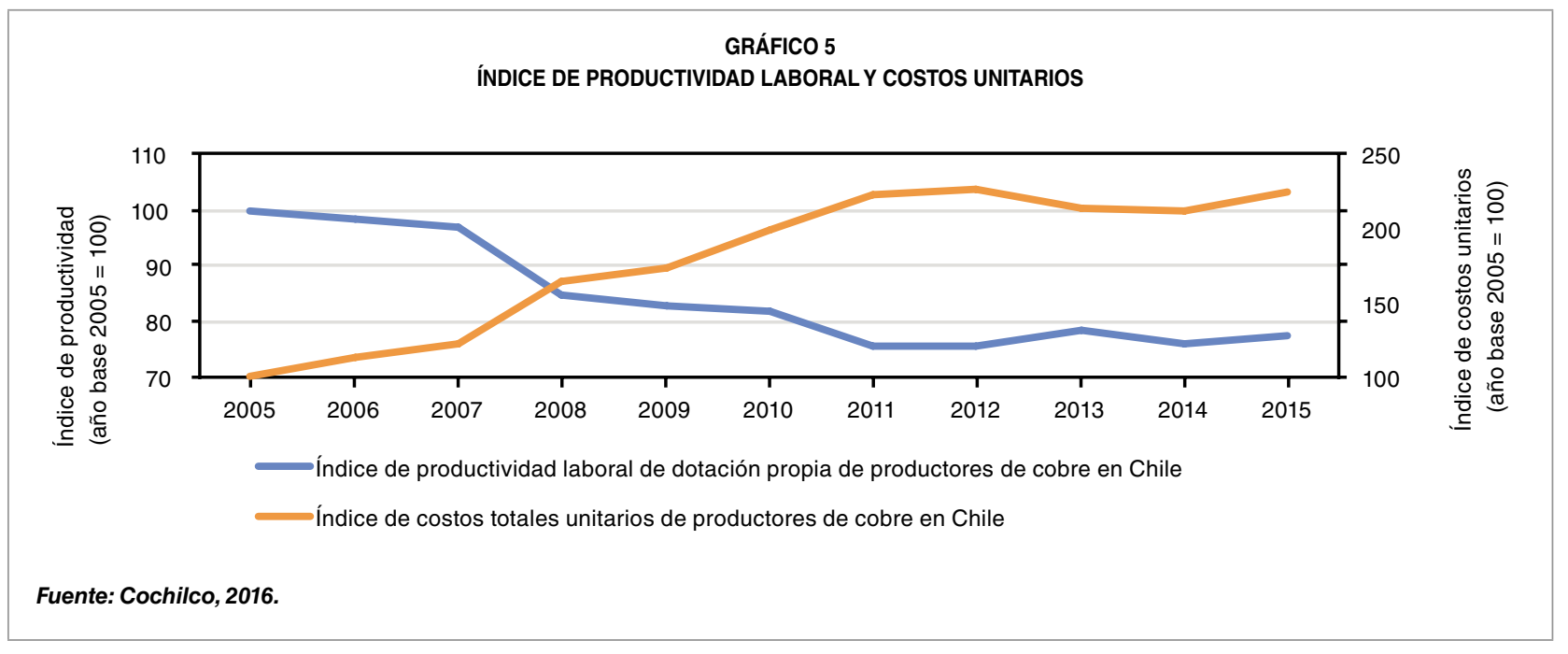

términos de productividad y costos. El abrupto término del superciclo minero puso en evidencia esta pérdida de competitividad y redefinió las incertidumbres y desafíos más relevantes para la industria.

La continuidad y crecimiento del sector requerirá ahora condiciones distintas a las actuales que permitan mitigar y controlar los principales riesgos que hoy en día afectan a la industria, así como aprovechar oportunidades aún no explotadas al máximo.

\section{Riesgos y oportunidades}

El término del superciclo puso en evidencia las falencias e incertidumbres que hoy afectan a la industria minera, así como oportunidades que no han sido aprovechadas. En esta reconfiguración de la industria aparecen seis aspectos relevantes que merecen ser tratados por el sector, bajo un esquema de trabajo conjunto con los entes gubernamentales. Estos son: productividad y costos, capacidad de renovación de proyectos, disponibilidad de insumos críticos, estrategia versus visión cortoplacista, Codelco como pilar del desarrollo minero del país y desarrollo de la mediana minería.

\subsection{Productividad y costos}

Los elevados precios de los commodities durante el superciclo marcaron el comienzo de una carrera entre las compañías mineras por aumentar la capacidad para poder abarcar la creciente demanda y obtener réditos de los altos precios, pero, en el camino, se perdió de vista dos aspectos operacionales fundamentales para el negocio: productividad y costos. En el Gráfico 5 se muestra el índice de productividad $^{7}$ de la Gran Minería Privada de cobre en Chile (GMP) ${ }^{8}$ más Codelco. Solo en el periodo 2005-2015 la productividad ha caído un 22,4 por 100 . Por otra parte, los costos totales unitarios ${ }^{9}$ de la GMP más Codelco han aumentado en un 125 por 100.

A lo anterior se suma el deterioro intrínseco que todo yacimiento minero experimenta en el tiempo (distancias de recorridos más largas, mayor dureza de roca, decaimiento de leyes (contenido unitario de mineral en el material extraído), aumento de consumo de insumos, $\triangleright$

7 Calculado a partir del cociente entre producción de cobre de mina y la dotación promedio de personal propio.

8 GMP corresponde al grupo de las diez empresas de la Gran Minería Privada del cobre, las cuales representan el 90 por 100 de la producción nacional.

9 Incluyen costos de explotación, gastos de administración y ventas y otros operacionales, gastos financieros y otros gastos no operacionales. Costos unitarios calculados con volúmenes de producción de cobre fino. 


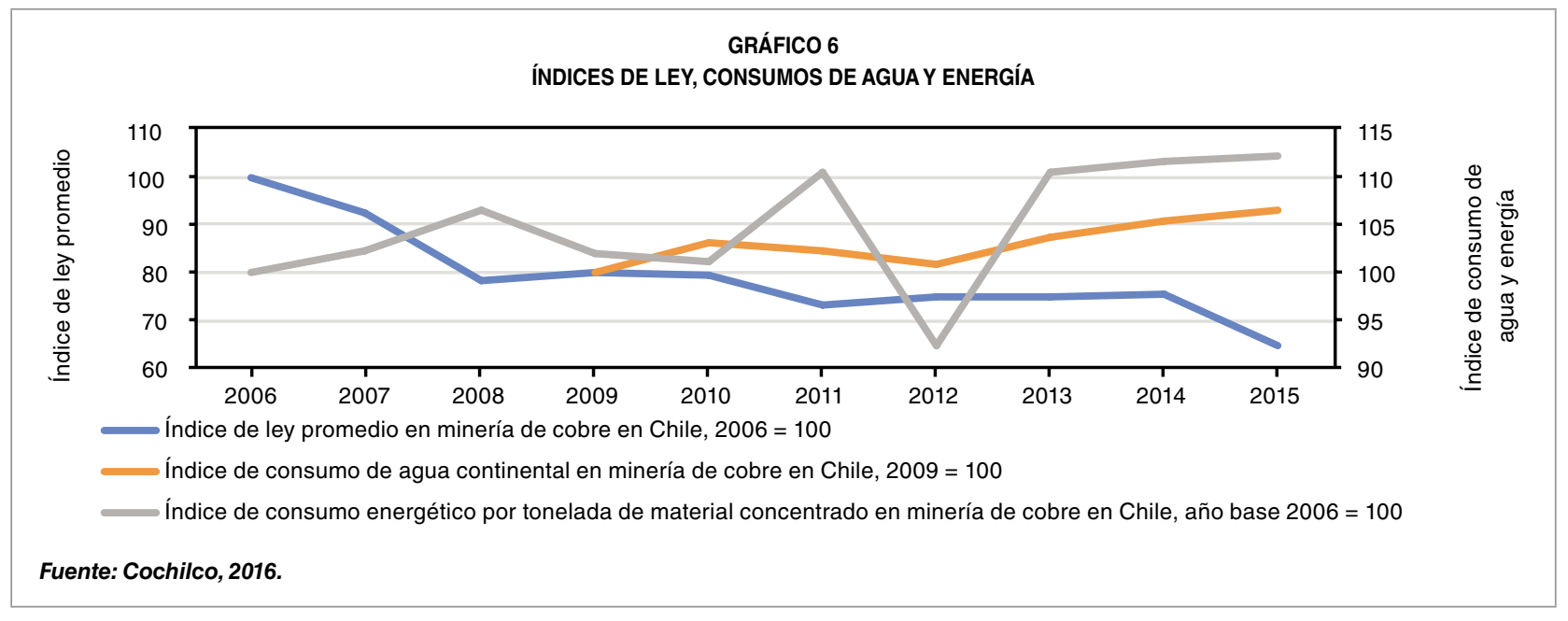

etcétera). En el Gráfico 6 se ilustra que el índice de leyes promedio ha caído un 35 por 100 sobre el periodo de análisis. Mientras tanto, el índice de consumo total de agua continental y el índice de consumo eléctrico por tonelada procesada han aumentado en un 7 por 100 y 12 por 100 respectivamente ${ }^{10}$. Todos estos indicadores reflejan el claro deterioro que han experimentado variables clave en el negocio minero.

El término del superciclo llevó a que las operaciones implementaran medidas de gestión de rápido impacto, como reducción de personal, disminución de beneficios y renegociación de contratos. Estas medidas son fáciles de implementar en poco tiempo y han permitido contrarrestar la caída de los ingresos en el corto plazo. Sin embargo, hoy las compañías se ven enfrentadas a la necesidad de ir más allá en la senda de reducción de costos y aumento de productividad, lo que requiere medidas de gestión más complejas.

\subsection{Capacidad de renovación de proyectos}

La geología hace de Chile un país con un enorme potencial en lo que a cobre y sus

\footnotetext{
10 Índices elaborados por Plusmining con base en información de la Comisión Chilena del Cobre.
}

subproductos se refiere. Sin embargo, la probabilidad de descubrir un recurso minero de clase mundial es cada vez menor. Incluso con presupuestos de exploración más elevados que hace veinte años, se ha vuelto más difícil encontrar yacimientos de grandes volúmenes, con buenas leyes y relativamente superficiales. No obstante, que no se encuentre este tipo de yacimientos no necesariamente significa que no existan, sino que probablemente se hallen a mayores profundidades o en ubicaciones aún más remotas que las actuales operaciones, lo que resta atractivo económico al yacimiento.

El Gráfico 7 indica la cartera de proyectos ${ }^{11}$ mineros de Chile y Perú para la siguiente década y dónde se diferencia aquella inversión greenfield $^{12}$ del resto. Como se puede observar, a pesar de que la cartera de proyectos de Chile es mayor que la de Perú, en términos de nuevos proyectos, Perú cuenta con una cartera superior a Chile.

Lo anterior pone en evidencia el hecho de que, si bien Chile es aún un país atractivo para la inversión y con una geología privilegiada, $\triangleright$

\footnotetext{
11 La cartera bajo análisis considera todos los proyectos con al menos estudios de prefactibilidad.

12 Proyectos mineros nuevos. Se diferencia de los proyectos brownfield, que corresponden a expansiones de proyectos ya existentes y que son muy comunes en el negocio minero.
} 

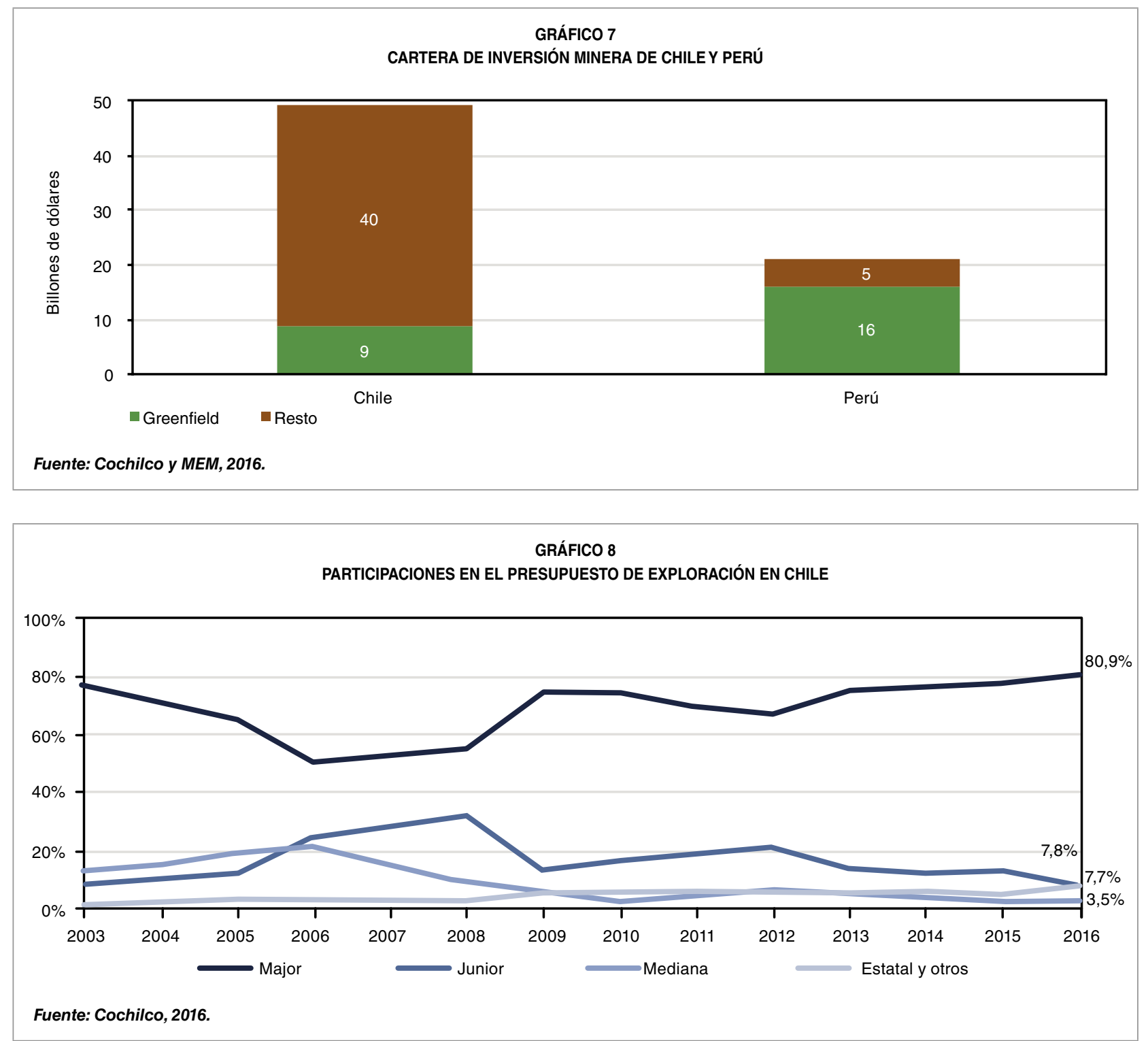

el cobre existe también de forma abundante en algunos otros lugares, por lo que cada país compite por los capitales para la exploración y desarrollo minero. Así lo demuestran los resultados de la Encuesta a Compañías Mineras 2015 realizada por el Instituto Fraser, Canadá. En ella se publica el índice de atractivo para la inversión en exploración ${ }^{13}$, en donde Chile cae del puesto 24, en 2011, al 56 en 2015 (Taylor \& Kenneth, 2016).

13 Índice que considera factores geológicos y de política pública, como la fiscalidad y la incertidumbre regulatoria, para evaluar el atractivo para la inversión en exploración por jurisdicción.
Por otra parte, como indica el Gráfico 8, las empresas majors ${ }^{14}$ en Chile son responsables del mayor gasto en exploración (alrededor del 75-80 por 100 en los últimos cinco años), el cual está sobre el promedio mundial del 53 por 100. Además, las juniors ${ }^{15}$ concentran una porción menor del total de exploración.

Dos lecturas se pueden extraer a partir de lo anterior. En primer lugar, las majors están principalmente enfocadas a mejorar la $\triangleright$

14 Empresas dedicadas a la operación de los proyectos mineros.

15 Empresas especialistas dedicadas exclusivamente a la exploración minera. 
información de sus actuales operaciones. En segundo lugar, la poca participación de las empresas juniors, especialistas en exploración, pone en evidencia limitaciones en la normativa que regula la actividad exploratoria en Chile. El actual Código de Minería ha generado en el tiempo efectos indeseados derivados de excesos en la mantención de la propiedad minera y poca movilidad de la misma, limitando fuertemente el atractivo país para las juniors, reduciendo la actividad exploratoria grassroot ${ }^{16}$.

En definitiva, existe el riesgo de que -de persistir la disminución en la tasa de descubrimiento de nuevos yacimientos de calidad en Chile- se afecte su lugar de privilegio en la industria mundial del cobre y el potencial que este sector tiene para seguir impulsando su economía en el mediano y largo plazo. Por el contrario, dado que estas restricciones han operado durante muchos años, es posible prever que introduciendo cambios responsables en el Código de Minería y aplicando incentivos para la actividad se produciría una profunda reactivación de la actividad de exploración en Chile, pudiendo resultar en el largo plazo en una mayor cartera de proyectos de calidad que brinden sustentabilidad al sector minero.

\subsection{Disponibilidad de insumos críticos}

Chile afronta desafíos complejos respecto a dos insumos muy relevantes, no tan solo para la industria minera, sino para la industria en su totalidad y la sociedad chilena. Estos son el agua y la energía eléctrica.

16 Primera etapa de exploración que tiene como objetivo descubrir nuevos yacimientos con potencial económico.
Respecto al agua, para la minería del cobre es un insumo crítico, y el sector ha ido aumentando su consumo. Sin embargo, su disponibilidad en el norte desértico del país (donde se concentra la minería) es muy escasa. Una forma en que la industria minera ha combatido este problema es a través de la construcción de plantas desalinizadoras; solo en la última década se han construido más de una decena de plantas dedicadas a la minería. Se espera, además, que en 2020 se construyan veinte plantas más, tanto para fines industriales como para consumo humano. Sin embargo, es un costo adicional con el que los actuales y futuros proyectos tendrán que lidiar.

Otro insumo muy sensible para el sector es el de la electricidad. La actividad minera es muy intensiva en el consumo eléctrico, el cual ha ido en aumento en el tiempo. Dada la completa escasez de recursos energéticos fósiles y las crecientes exigencias contra la emisión de gases, diversas compañías mineras han tomado carta en el asunto mediante alianzas con generadoras de energías renovables no convencionales (ERNC) ${ }^{17}$. No obstante, aunque ha aumentado de forma importante la capacidad instalada de ERNC, este tipo de energías aún tienen que lidiar con el desafío de entrega de flujo constante de energía (muy relevante para la industria minera).

Pese a que el sector minero ha tomado un rol activo respecto al suministro de agua y electricidad, su disponibilidad a bajo costo sigue siendo un riesgo latente. Chile tiene que resolver desde una perspectiva global y definitiva estos temas con el objetivo de asegurar el suministro de estos insumos al sector industrial y a la sociedad a costos competitivos.

17 Han mostrado una gran aceptación por parte de la ciudadanía chilena. 


\subsection{Estrategia versus visión cortoplacista}

Chile ha sido exitoso en desarrollar un sector minero de primer nivel mundial, pero paradójicamente no ha logrado vincularlo a otros sectores de la economía, la política y la sociedad chilena, falencia que es de responsabilidad compartida entre el sector político, la sociedad y las compañías. Lo anterior es crucial para explicar que, en la discusión pública sobre los desafíos de la minería, predomine una excesiva mirada de corto plazo y con un alcance limitado.

En Chile, las empresas mineras en general siguen una estrategia de bajo perfil, en la creencia que así es menos probable verse involucradas en temas relacionados con demandas sociales o tributarias. En el plano público, históricamente el Estado mostró poca proactividad como articulador y conductor del sector, lo que se tradujo en escasas iniciativas legislativas desarrolladas con el objetivo de brindar soluciones definitivas a los desafíos de la industria. Como resultado de lo anterior, durante muchos años los actores políticos y de la industria han estado desarticulados y sin una agenda clara que desarrollar. En la actualidad se han implementado iniciativas como la creación de entidades, como Alianza Valor Minero o el programa nacional de minería Alta Ley, que buscan corregir esta desarticulación. No obstante, el sector aún está a la espera de que estas iniciativas materialicen un impacto real y positivo para el sector.

Por otra parte, en contraste con el desarrollo logrado por ciertas economías ricas en recursos naturales, como Canadá y Australia, casos como el chileno, que no ha logrado el desarrollo, se asocian a un predominio de un comportamiento de búsqueda de renta en el corto plazo (rent seeking). Esto anula los incentivos al emprendimiento y la innovación técnica, arrastrando a las sociedades a una posición cómoda, de statuquo, que a la larga afecta a su competitividad.

Por lo tanto, es relevante para el país contar con un sector minero que involucre de forma articulada al Estado, las compañías y la comunidad, para así afrontar sus desafíos y fortalecer su rol como motor para el desarrollo del país, privilegiando visiones de mediano y largo plazo.

\subsection{Codelco como pieza fundamental del modelo minero}

Chile cuenta con un «modelo mixto» en el que coexiste la explotación minera pública (a través de Codelco) y la privada. Lo anterior permite al país contar con una mayor producción total al combinar el aporte del sector privado con la base que aporta la empresa estatal, lo que aumenta no solo la generación de renta, sino también la base productiva sobre la cual podría desarrollarse exitosamente una industria de bienes y servicios que diversifique y amplíe el efecto de la minería en la economía del país. Adicionalmente, esta coexistencia aumenta la legitimidad de la actividad minera en el país y establece una comparación implícita de la gestión de las compañías y del aporte que realizan al país.

Por lo tanto, Codelco es una piedra angular en el modelo mixto de la industria minera en Chile cuyo rol es crucial para brindar sustento a esta alianza público-privada. Sin embargo, en la última década, Codelco ha incrementado sus desafíos debido a que sus extraordinarios yacimientos -algunos de ellos explotados durante más de un siglo- se enfrentan a inevitables decaimientos que requieren grandes inversiones, lo cual pone a prueba su conducción y el $\triangleright$ 
feble esquema de capitalización que le ofrece su dueño.

Es fundamental para que el sector pueda obtener réditos de una figura como Codelco que esta pueda operar de forma autónoma ${ }^{18}$ en los ciclos políticos, permitiéndole desplegar su inmenso potencial de negocios. Por otra parte, si Codelco no cuenta con una capacidad de financiamiento clara y previsible ${ }^{19}$, su gestión se debilitará seriamente $y$, como se sabe, en minería es por definición de largo plazo. Para que Codelco cuente efectivamente con un financiamiento de largo plazo es necesario que quien tome dicha decisión no esté sujeto a consideraciones políticas o de corto plazo; asegurando así que los criterios de capitalización de Codelco correspondan a las necesidades técnicas de la compañía.

\subsection{Desarrollo de la mediana minería}

La mediana minería agrupa a una treintena de compañías que, en conjunto, exportan más que otras industrias relevantes de Chile, como la del vino o el salmón. Por muchos años se ha esperado que estas empresas de la mediana minería se desarrollen con fuerza y tengan un papel más relevante como vectores de desarrollo del país, pero no ha ocurrido.

Existen elementos en la actualidad, tales como la falta de descubrimiento de cuerpos minerales masivos y el creciente aumento en la complejidad del manejo de operaciones a gran escala (debido, entre otras cosas, al gran poder que los sindicatos mineros pueden

18 Chile, en los últimos años, ha avanzado en materia de autonomía y visión de largo plazo en sus instituciones en aspectos como política monetaria, a través de un banco central autónomo.

19 Codelco debe proporcionar sus utilidades al Gobierno. Además, la Ley Reservada del Cobre obliga a Codelco a destinar el 10 por 100 de los ingresos por venta de cobre y sus derivados a las Fuerzas Armadas. lograr o a dificultades en la obtención de la licencia ciudadana), que permiten inferir que el desarrollo de la mediana minería tiene un gran potencial, el cual permitiría activar operaciones de recursos mineros medianos hoy no explotados suficientemente y también estimular la vinculación con otros sectores económicos como los de servicios financieros, contables y comerciales ligados a la minería, ya que las compañías mineras se integran más fácilmente en empresas domésticas.

\section{Conclusión}

La minería, principal actividad económica de Chile, está en una fase crucial para su crecimiento futuro. Para un impulso decisivo de esta actividad es necesario controlar, en primer lugar, las incertidumbres que hoy en día amenazan al sector. Segundo, es preciso que, a partir de los cambios regulatorios necesarios y de la proactividad de instituciones gubernamentales claves para la industria, se aprovechen las oportunidades que Chile tiene, asegurando la sustentabilidad productiva de la nación y brindando la oportunidad para que se desarrolle una industria de bienes y servicios ligados al sector minero y que amplifique el impacto de la minería en la economía del país. Logrando lo anterior, Chile mostraría al mundo, por un lado, la madurez que ha conseguido en el manejo de esta industria, consagrándose no solo como un país productor, sino también como exportador de bienes y servicios ligados a la minería y ejemplo dentro del continente. Por otro lado, le permitiría disponer del sector como plataforma que facilite el mantenimiento de una economía sustentable para avanzar así hacia el tan anhelado desarrollo.

Muy relevante será para la solución de estos desafíos la capacidad que Chile tenga de $\triangleright$ 
superar la paradójica desconexión entre la sociedad y esta actividad, y por otro lado instalar en la discusión pública la gran oportunidad que representa la posibilidad de generar una plataforma de desarrollo a largo plazo a partir de la minería.

\section{Bibliografía}

[1] COMISIÓN CHILENA DEL COBRE (2016). Catastro de empresas exploradoras 2016. Santiago: Cochilco.

[2] COMISIÓN CHILENA DEL COBRE (2016). Informe Inversion Minera 2016. Santiago: Cochilco.

[3] COMISIÓN CHILENA DEL COBRE (2016). Anuario de Estadísticas del Cobre y Otros Minerales 1996-2015. Santiago: Cochilco.
[4] COMISIÓN CHILENA DEL COBRE (2016). Mercado del Renio y su Producción en Chile. Santiago: Cochilco.

[5] GAJARDO, M. y VIVALLO, W. (2009). Evolución de las Reservas y Recirsos de Cobre, Molibdeno, Oro, Plata, Nitrato y Yodo en Chile, 2001-2007. Santiago de Chile: Sernageomin (Servicio Nacional de Geología y Minería).

[6] JACKSON, T. y GREEN, K.P. (2016). Survey of Mining Companies. Vancouver: Fraser Institute.

[7] MINISTERIO DE ENERGÍA Y MINAS DEL PERÚ (MEM) (2016). Catastro Proyectos Mineros Perú. Lima: MEM.

[8] SERVICIO NACIONAL DE GEOLOGÍA Y MINERÍA DE CHILE (2003). Mapa Geológico de Chile: Versión Digital. Santiago: Sernageomin.

[9] UNITED STATE GEOLOGICAL SURVEY (2017). Mineral Commodity Summaries 2017. Reston: USGS. 



\section{NORMAS DE ESTILO DE PUBLICACIÓN}

La persona o personas interesadas en presentar un artículo para su publicación en el Boletín de Información Comercial Española (BICE) deberán enviar el artículo en formato Microsoft Word a la dirección de correo electrónico revistasice.sscc@comercio.mineco.es

El documento debe cumplir las siguientes características:

1. Ser material original no publicado ni presentado en otro medio de difusión.

2. La extensión total del trabajo (incluyendo cuadros, gráficos, tablas, notas, etcétera) no debe ser inferior a 15 páginas ni superior a 20. La fuente será Times New Roman, tamaño 12 y espaciado doble. Estar paginado en la parte inferior derecha de cada página.

3. En la primera página se hará constar el título del artículo que deberá ser breve, claro, preciso e informativo y la fecha de conclusión del mismo. Nombre y dos apellidos del autor o autores, filiación institucional, dirección, teléfono y correo electrónico de cada uno de ellos, así como la forma en que desean que sus datos aparezcan.

4. En la segunda página del texto se incluirá:

- El título.

- Un resumen del trabajo con una extensión máxima de 10 líneas con la siguiente estructura: objetivo, método y principal resultado o conclusión.

- De 2 a 6 palabras clave que no sean coincidentes con el título.

- De 1 a 5 códigos de materias del Journal of Economic Literature (clasificación JEL) para lo cual pueden acceder a la siguiente dirección electrónica:

https://www.aeaweb.org/jel/guide/jel.php

5. En las siguientes páginas se incluirán el texto, la información gráfica y la bibliografía con la siguiente organización.

- Se incluirá, por este orden, introducción, desarrollo, conclusiones y bibliografía y anexos si los hubiera. Los apartados y subapartados se numerarán en arábigos respondiendo a una sucesión continuada utilizando un punto para separar los niveles de división, según el siguiente modelo:

\section{Título del apartado}

\subsection{Título del apartado}

\subsubsection{Título del apartado}

\section{Título del apartado}

- Las notas de pie de página irán integradas en el texto y su contenido debe estar al final de su misma página en tamaño 10 y espacio sencillo.

- En un archivo Excel independiente se incluirá la representación gráfica (cuadros, gráficos, diagramas, figuras, etc.), que debe llevar título, estar numerada y referenciada en el texto.

En la parte inferior se incluirá la fuente de información y/o notas aclaratorias.

- Las citas de libros y artículos en el texto, se indicarán entre paréntesis con el apellido del autor y el año. Ej.: (Martínez, 1991).

- Las referencias a siglas deben ir acompañadas, en la primera ocasión en que se citen, de su significado completo.

- La bibliografía se ordenará alfabéticamente siguiendo las normas de la American Psychological Association (Harvard-APA): http://cibem.org/paginas/img/apa6.pdf

Libros

APELLIDOS, A.A. (año de publicación). Título del libro (edición) (volumen). Ciudad: Editorial.

Artículo en revista científica

APELLIDOS, A.A. (año de publicación). «Título del artículo». Título de la revista, volumen (número), números de páginas.

\section{Documento en línea}

APELLIDOS, A.A. u ORGANISMO (año, mes de publicación). Título, [en línea]. Ciudad: Editorial. Disponible en:

http://cenamb.rect.ucv.ve/siamaz/dicciona/canaima/canaima2.htm [Recuperado: 2000, 3 de junio]. 


ISSN 0214-8307

\section{SUSCRIPCIÓN ANUAL}

\begin{tabular}{|c|c|c|c|}
\hline \multicolumn{3}{|c|}{ BOLETÍN ECONÓMICO DE INFORMACIÓN COMERCIAL ESPAÑOLA (12 NÚMEROS) } \\
\hline & $\begin{array}{c}\text { ESPAÑA } \\
\mathbf{1} \text { año }\end{array}$ & $\begin{array}{c}\text { UNIÓN EUROPEA } \\
\mathbf{1} \text { año }\end{array}$ & $\begin{array}{c}\text { RESTO DEL } \\
\text { MUNDO } \\
1 \text { año }\end{array}$ \\
\hline SUSCRIPCIÓN & $65,00 €$ & $85,00 €$ & $85,00 €$ \\
\hline $\begin{array}{c}\text { Gastos de envío } \\
\text { España }\end{array}$ & $5,76 €$ & $24,36 €$ & $30,00 €$ \\
\hline $\begin{array}{c}\text { Más 4\% de IVA. } \\
\text { Excepto Canarias, Ceuta y Melilla }\end{array}$ & $2,83 €$ & & $115,00 €$ \\
\hline TOTAL & $73,59 €$ & $109,36 €$ & \\
\hline & & & \\
\hline
\end{tabular}

\section{EJEMPLARES SUELTOS}

\begin{tabular}{|c|c|c|c|}
\hline \multicolumn{4}{|c|}{ BOLETÍN ECONÓMICO DE INFORMACIÓN COMERCIAL ESPAÑOLA } \\
\hline & $\begin{array}{l}\text { ESPAÑA } \\
1 \text { ejemplar }\end{array}$ & $\begin{array}{l}\text { UNIÓN EUROPEA } \\
1 \text { ejemplar }\end{array}$ & $\begin{array}{c}\text { RESTO DEL } \\
\text { MUNDO } \\
1 \text { ejemplar }\end{array}$ \\
\hline NÚMERO SUELTO & $7,00 €$ & $9,00 €$ & $9,00 €$ \\
\hline $\begin{array}{l}\text { Gastos de envío } \\
\text { España }\end{array}$ & $0,48 €$ & $2,03 €$ & $2,50 €$ \\
\hline $\begin{array}{l}\text { Más } 4 \% \text { de IVA. } \\
\text { Excepto Canarias, Ceuta y Melilla }\end{array}$ & $0,30 €$ & & \\
\hline TOTAL & $7,78 €$ & $11,03 €$ & $11,50 €$ \\
\hline \multicolumn{4}{|c|}{ BOLETÍN ECONÓMICO DE INFORMACIÓN COMERCIAL ESPAÑOLA } \\
\hline & $\begin{array}{l}\text { ESPAÑA } \\
1 \text { ejemplar }\end{array}$ & $\begin{array}{l}\text { UNIÓN EUROPEA } \\
1 \text { ejemplar }\end{array}$ & $\begin{array}{l}\text { RESTO DEL } \\
\text { MUNDO } \\
1 \text { ejemplar }\end{array}$ \\
\hline $\begin{array}{l}\text { NÚMERO SUELTO } \\
\text { EXTRAORDINARIO }\end{array}$ & $12,00 €$ & $15,00 €$ & $15,00 €$ \\
\hline Gastos de envío España & $0,48 €$ & $2,03 €$ & $2,50 €$ \\
\hline $\begin{array}{c}\text { Más } 4 \% \text { de IVA. } \\
\text { Excepto Canarias, Ceuta y Melilla }\end{array}$ & $0,50 €$ & & \\
\hline TOTAL & $12,98 €$ & $17,03 €$ & $17,50 €$ \\
\hline
\end{tabular}

\section{DATOS}

Nombre y apellidos

Empresa

Domicilio

D.P.

N.I.F.

Teléf.

Email

\section{DATOS DEL EDITOR:}

NIF:S2800568D

Transferencia a la cuenta de ingresos por venta de publicaciones del Ministerio de Economía y Competitividad.

IBERCAJA. Calle Alcalá 29. 28014 MADRID (ESPAÑA) CÓDIGO CUENTA CLIENTE: 2085-9252-07-0330598330 CÓDIGO BIC DE IBERCAJA: CAZRES2Z

IBAN: ES47 2085-9252-07-0330598330

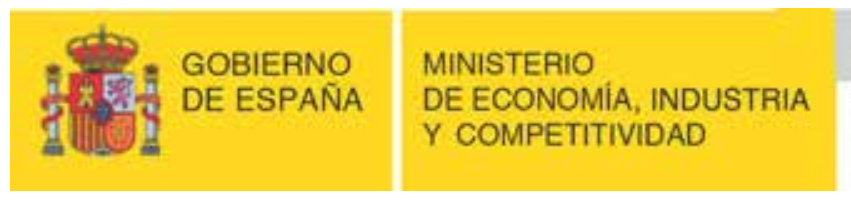


